Original Research Paper

\title{
Study the Effect of Extracted Low-Density Lipoprotein from Egg Yolk on the Cryopreservation of Nguni Bull Semen
}

\author{
${ }^{1,2}$ Mduduzi M. Tshabalala, ${ }^{1}$ Masindi Lottus Mphaphathi, ${ }^{1}$ Khathutshedzo A. Nephawe, \\ ${ }^{2}$ Cyril M. Pilane and ${ }^{1,2}$ Tshimangadzo L. Nedambale \\ ${ }^{I}$ Agricultural Research Council, Animal Production, Germplasm Conservation and Reproductive Biotechnologies, Private Bag \\ $X$ 2, Irene, 0062, RSA \\ ${ }^{2}$ Agricultural Research Council, Animal Production, Germplasm Conservation and Reproductive Biotechnologies, \\ Private Bag X 2, Irene, 0062, South Africa
}

\author{
Article history \\ Received: 19-02-2021 \\ Revised: 21-05-2021 \\ Accepted: 28-05-2021 \\ Corresponding Author: \\ Masindi Lottus Mphaphathi \\ Agricultural Research Council, \\ Animal Production, \\ Germplasm Conservation and \\ Reproductive Biotechnologies, \\ Private Bag X 2, Irene, 0062, \\ RSA \\ Email: masindim@arc.agric.za
}

\begin{abstract}
The mechanism on how egg yolk (EY) helps sperm to survive the low temperature outside the animal body during cryopreservation and thawing process is not yet known. It is usually believed that the Low-Density Lipoprotein (LDL) is the major component that provides protection. The present study was undertaken to assess the cryo-protective effect of different concentrations $(6,8,10$ and $12 \%)$ of LDL and $20 \% \mathrm{EY}$ (control) on sperm motility, morphological parameters and cleavage rate of the cows ovaries following freezing and thawing. Semen was collected from five Nguni bulls aged 2-4 years of known and proven fertility with an aid of electro-ejaculated and immediately transported to the laboratory. The LDL was extracted from the chicken egg yolk and further processed. The collected semen samples were evaluated for microscopic sperm motility and morphological parameters. Thereafter, the semen samples were diluted with different concentrations $(6,8,10$ and $12 \%)$ of LDL and $20 \%$ EY (control) extender supplemented with $12 \%$ Glycerol as a cryoprotectant. Semen samples were loaded into 0.25 straws, placed into a controlled rate programmable freezer and stored in liquid nitrogen tank. Following semen thawing, sperm motility, morphological were evaluated. Furthermore, in vitro fertilization (IVF) was conducted on cow's oocytes to test the fertilizing ability of semen diluted with LDL on the cleavage rate. Data was analyzed with the aid of ANOVA. Furthermore, treatment means were compared with the Least Significance Difference (LSD) test. The percentage of motility parameters and percentage of live sperm with intact plasma membrane, acrosome membrane and DNA integrity were significantly higher $(P<0.05)$ in semen diluted with $20 \% \mathrm{EY}$ (control) and 8\% compared to semen diluted with (6,10 and 12\% LDL). Cleavage rates were significantly higher $(P<0.05)$ higher in extender containing 20\% EY (control) and $8 \%$ LDL. In conclusion, $8 \%$ LDL extender can be used as an alternative to $20 \%$ EY extender in preserving the sperm motility rate, percentage of live sperm, intact plasma membrane, acrosome, DNA integrity and fertilizing ability of frozen-thawed Nguni bull semen.
\end{abstract}

Keywords: Cryopreservation, DNA Integrity, Egg Yolk, Low-Density Lipoprotein, In vitro Fertilization

\section{Introduction}

The indigenous Nguni cattle breed is adapted to South African (SA) environment; it is hardy with superior genetic material. The indigenous Nguni cattle breed is multi-coloured or uncolored (brown, grey, red, white, black cream and dun). The Nguni cattle have traits that make them favourable for resource-poor cattle farmers of
SA. It is further tolerant to nematodes, ticks and tick-borne diseases, has good temperament, good walking ability and can be in good condition even during winter season (Spickett et al., 1989; Muchenje, 2007; Ndlovu, 2007). These characteristics make the Nguni breed to be conserved through utilization. The Nguni cattle gene pool is almost on the verge of extinction due to crossbreeding with other exotic genotypes. This leads to the need to 
cryopreserve its genetic material. Cryopreservation is the freezing of cells or tissues at sub-zero temperatures, typically $-196^{\circ} \mathrm{C}$, until future use. Cryopreservation has been practiced as a routine technique to preserve bovine sperm for artificial insemination (Watson et al., 1995). This technique results in the loss of $40-50 \%$ of viable sperm during the freeze-thaw process and little improvement over the last decades has been reported (Prathalingam et al., 2006). Cold shock, osmotic stress, ice crystal formation or oxidative damage is the main causes of sperm cryo-injury which lead to the loss of sperm viability and fertility (Mazur, 1984).

This is mainly due to freeze-thawing process which exposes the semen to thermal shock that causes a detrimental effect to the structure, biochemical and functional damage leading to a reduction of sperm motility, membrane integrity, damage to DNA, membrane damage and ultimately a reduction in the fertilizing ability of sperm (Salamon and Maxwell, 1995; Tekin et al., 2006). The establishment of a cryoprotectant such as egg yolk (EY) added a new era in semen cryopreservation. The EY serve as the most effective cryoprotective agent of freezing extender that protects the sperm against cold shock (Bergeron et al., 2005). The EY has been successfully used as a cryoprotectant for cryopreservation of bull semen. Higher survival and fertility rates of bull sperm with $20 \%$ egg yolk have been reported. Despite the successes, there are reservation for its use due to possible risks of contamination and loss of semen quality (Thun et al., 2002). Others have suggested that the components of EY, like the Low-Density Lipoprotein (LDL), have a better cryoprotective effect than EY (Bencharif et al., 2008). In particular, the LDL has been implicated as the main EY component leading to improved semen quality following cryopreservation (Amirat et al., 2004; Bencharif et al., 2008). During the freeze-thawing process, LDL forms a protective cover at the surface of the sperm membrane (Bergeron et al., 2004). The LDL interact specifically with Bovine Seminal Plasma (BSP) proteins and decreased the binding of the major proteins of BSP to the sperm, preventing lipid efflux from the sperm membrane. The LDL may offer protection to sperm by reducing the deleterious effect of seminal plasma proteins on sperm membranes. achieved acceptable sperm motility results when the EY was substituted with the $8 \%$ (w/v) LDL in frozenthawed bull semen. Therefore, the objectives of this study were to evaluate the effect of different concentrations of LDL on sperm motility, viability, membrane integrity, acrosome integrity and DNA integrity and to determine the fertilizing potential of the semen diluted with LDL on the cleavage rate.

\section{Materials and Methods}

\section{Study Site}

The study was conducted at the Agricultural Research Council-Irene at Germplasm Conservation and Reproductive Biotechnology laboratory. The area is located at 25'53' 59.6" south latitude and $28^{\circ} 12^{\prime} 51.6^{\prime \prime}$ east longitude in Pretoria, SA and situated on the Highveld with altitude of $1525 \mathrm{~m}$ above sea level. The experimental procedures were approved by the Tshwane University of Technology (AREC2015/10/004) and the Agricultural Research Council Ethics Committee (APIEC15/041).

\section{Nguni Bulls Management}

The Nguni bulls ( $n=5)$, aged between two to four years were utilized for semen collection. All bulls were maintained on natural pastures and water was provided ad libitum. Semen was collected twice per week from five Nguni bulls for five weeks with the aid of an electro-ejaculator into a $15 \mathrm{~mL}$ Falcon tube during the natural breeding season and ten replicates were done in this experiment after collection, the semen samples were kept in thermoflask that contained warm water at $37^{\circ} \mathrm{C}$ and transported to the laboratory for macro and microscopically semen analysis.

\section{Extraction of Low-Density Lipoprotein}

The LDL was extracted according to the technique defined by. Fresh eggs were collected and broken manually by separating the egg yolk from the albumin. Egg yolk was diluted three times with an isotonic saline solution $(0.17 \mathrm{M}$ $\mathrm{NaCl}$ ) and stirred using a magnetic stirrer for $1 \mathrm{~h}$ before being centrifuged at $10,000 \times \mathrm{g}$ for $45 \mathrm{~min}$ at $4^{\circ} \mathrm{C}$. The plasma (supernatant) was collected and diluted mixed $40 \%$ ammonium sulphate (1:1 ratio) to precipitate livetins. After $1 \mathrm{~h}$ of stirring at $4^{\circ} \mathrm{C}$, the mixture was centrifuged at 10,000 $\mathrm{x} g$ for $45 \mathrm{~min}$ to separate the plasma from the granules. The granules were discarded and the plasma was dialyzed for 12 $\mathrm{h}$ against distilled water in order to remove ammonium sulphate. After the complete removal of ammonium sulphate, the mixture was centrifuge again at 10,000 $\mathrm{x} g$ for $45 \mathrm{~min}$ at $4^{\circ} \mathrm{C}$ and the floating residue, which is rich in LDL, was collected.

\section{Bulls Semen Evaluation}

Briefly, $5 \mu \mathrm{L}$ of diluted semen was pipetted on a microscope slide and covered with a warm glass slide (76-26-1 mm, Germany) over the microscope warm plate (Omron) adjusted at $37^{\circ} \mathrm{C}$. The sperm motility rates were evaluated before and after freeze-thawing by using a Sperm Class Analyzer ${ }^{\circledR}$ system (Microptic, Spain) at the magnification of $\mathrm{x} 10$ (Nikon, China). The sperm morphology was recorded after staining the semen samples with Eosin-nigrosin, Acridine-Orange, FITC-PSA and host solution on a microscope slide. The stained-glass 
slide was placed on the microscope table for evaluation. Before evaluation, a drop of immersion oil was poured on the stained-glass slide, a fluorescent microscope (Olympus, Corporation BX 51FT, Tokyo, Japan) was used at x 100 magnification and a total of 200 sperm were counted per slide.

\section{Bulls Semen Dilution, Freezing and Thawing}

Freshly collected semen was divided into five equal segments. One segment was diluted (1:1) with the egg yolk citrate extender, without a cryoprotectant (fraction A) and stored at $5^{\circ} \mathrm{C}$ for $2 \mathrm{~h}$. Subsequently, a second (fraction $\mathrm{B}$ ) dilution (1:2) with egg yolk citrate extender containing $12 \%$ of Glycerol (GLY) was further equilibrated for another $2 \mathrm{~h}$ at $5^{\circ} \mathrm{C}$. The other four equal segments were diluted $(1: 1)$ with different concentration $6,8,10,12 \%$ of LDL, without a cryoprotectant (fraction A) and stored at $5^{\circ} \mathrm{C}$ for $2 \mathrm{~h}$. Subsequently, a second (fraction $\mathrm{B}$ ) dilution $(1: 2)$ with different concentration $6,8,10,12 \%$ of LDL containing $12 \%$ of GLY was further equilibrated for $2 \mathrm{~h}$ at $5^{\circ} \mathrm{C}$. Following the $2 \mathrm{~h}$ of equilibration with fraction $\mathrm{B}$, the semen samples were loaded into $0.25 \mathrm{~mL}$ polyvinyl chloride straws, sealed and placed horizontally into a controlled rate programmable freezer from 5 to $-5^{\circ} \mathrm{C}$ at $0.008^{\circ} \mathrm{C}$ min and from -4 to $-130^{\circ} \mathrm{C}$ at $6^{\circ} \mathrm{C}$ min (Seshoka et al., 2012). When the target temperature of $-130^{\circ} \mathrm{C}$ was reached, the frozen straws of the semen samples were plunged directly into the liquid nitrogen tank $\left(-196^{\circ} \mathrm{C}\right)$ for storage. A week after storing the frozen semen sample in liquid nitrogen tank, the frozen straws were thawed in a water bath at $37^{\circ} \mathrm{C}$ for $1 \mathrm{~min}$. Thawed semen samples were evaluated for sperm motility traits using Sperm Class Analyzer ${ }^{\circledR}$ system and morphological traits using a fluoresce microscope.

\section{Evaluation of Live and Dead Sperm from Nguni Bulls}

The live and dead sperm of the fresh and frozenthawed semen were determined using eosin/nigrosine swelling (Onderstepoort, Faculty of Veterinary Science Pharmacy, SA) and $5 \mu \mathrm{L}$ of raw semen was mixed with $20 \mu \mathrm{L}$ of Eosin-Nigrosin swelling. However, $7 \mu \mathrm{L}$ of the mixture was smeared on a glass slide. The stained slides were allowed to dry at room temperature before being placed on a microscope table and a drop of immersion oil was placed on the slide to evaluate live and dead sperm using a fluorescent microscope (Olympus, BX 51FT, Tokyo, Japan) under $\times 100$ magnification. Live and dead sperm were determined by evaluating the percentage of sperm that absorbed the swelling, those ones that absorbed the swelling were considered as dead, while the ones that did not absorbed the swelling were considered live and 200 sperm were counted per bull, per replicate.

\section{Evaluation of Sperm Membrane Integrity}

Sperm membrane integrity was evaluated by using a hypo-osmotic swelling test before and after freezing of the Nguni semen samples. A semen volume of $0.1 \mathrm{~mL}$ was mixed with $1 \mathrm{~mL}$ of hypo-osmotic swelling $(8.71 \mathrm{~g} / \mathrm{L}$ of fructose and $4.47 \mathrm{~g} / \mathrm{L}$ of sodium chloride, $\mathrm{pH}$ 8.05) (Sigma - Aldrich, SA) (Pty) (Ltd) and incubated for $1 \mathrm{~h}$ at $37^{\circ} \mathrm{C}$ (Naing et al., 2010). Following incubation, a drop of diluted semen was placed on a glass slide, covered with a cover slip and analysed under a phase contrast microscope (x 100). A total number of 200 sperm were analysed from each slide. Sperm with a swollen and coiled tail were recorded as intact (Naing et al., 2010).

\section{Evaluation of Sperm Acrosome Integrity}

The Nguni bull sperm acrosome integrity was determined using isothiocyano-fluoresceinated Pisumsativum agglutinin (FITC-PSA) (Partyka et al., 2010). Briefly, $20 \mu \mathrm{L}$ of the diluted semen was suspended in $500 \mu \mathrm{L}$ of Phosphate Buffer Saline (PBS) and centrifuged for $10 \mathrm{~min}$ at $100 \mathrm{xg}$, the supernatant was discarded. The sperm pellet was resuspended in $250 \mu \mathrm{L}$ of PBS. One drop of the re-suspended semen was smeared on a glass slide and air dried; this was followed by fixing the air-dried slide with acetone for $10 \mathrm{~min}$ at $4^{\circ} \mathrm{C}$. The smears of sperm suspensions were mounted with FITC-PSA swelling (50 ug/mL in PBS swelling) and kept in a dark room for $30 \mathrm{~min}$. The slide was then rinsed with a PBS swelling and examined under a fluorescence microscope. A total of 200 sperm were evaluated from each stained glass slide for acrosome integrity.

\section{Evaluation of Sperm DNA Integrity}

The sperm DNA integrity was determined by using a method described by Tejada et al. (1984). Acridine Orange (Sigma-Aldrich, St Louis, MO, USA) was used to analyse the DNA integrity of the Nguni bull sperm. Briefly, $20 \mu \mathrm{L}$ of the fresh and frozen-thawed semen was transferred to a $15 \mathrm{~mL}$ conical tube and washed three times with PBS using the centrifugation machine. A drop of the sperm pellet was smeared on a glass slide using a pipette tip to avoid breakage of the sperm and allowed to air-dry for ten minutes. The smeared glass slide was then fixed for $1 \mathrm{~h}$ in ethanol-aceton (1:1) inside a plastic container lid at $4{ }^{\circ} \mathrm{C}$ and allowed to air-dry for few minutes. The glass slide was then stained with Acridine-Orange $(0.19 \mathrm{mg} / \mathrm{m})$ for $7 \mathrm{~min}$ at the room temperature in the dark. The stained glass slide was gently rinsed with distilled water and air dried, then viewed under a fluorescence microscope (Olympus, BX 51FT, Tokyo, Japan) at $\times 100$ magnification under oil immersion. A total number of 200 sperm were evaluated by using a fluorescence microscope (Olympus, BX 51FT, Tokyo, Japan) under $\times 100$ magnification. Sperm with an intact (double stranded) DNA fluorescence green, while sperm with a damaged 
DNA fluorescence red or yellow-orange to red and these sperm were counted as sperm with a single stranded DNA.

\section{In Vitro Fertilization of Oocytes}

Matured oocytes were placed in the fertilization (Bracket and Oliphant IVF) medium. Frozen- thawed semen diluted with $8 \%$ low-density lipoprotein and $20 \%$ egg was used. Semen was thawed in a water bath at $37^{\circ} \mathrm{C}$ for $1 \mathrm{~min}$. Semen was washed twice by centrifugation (800 $\mathrm{g}$ for $8 \mathrm{~min}$ ) in a pre-warmed Bracket and Oliphant washing medium. Thereafter, the supernatant was removed with a serological pipette. For fertilization, $50 \mu \mathrm{L}$ of the diluted bull semen solution with a sperm concentration of approximately $1 \times 10^{6} / \mathrm{mL}$ was utilized to inseminate each $50 \mu \mathrm{L}$ droplets (final volume of $100 \mu \mathrm{L}$ ). Subsequently, oocytes together with sperm were incubated for $18 \mathrm{~h}$ at $38.5^{\circ} \mathrm{C}$ in $5 \% \mathrm{CO}_{2}$ in air. Following in vitro fertilization, presumptive zygotes were washed by vortexing for $1 \mathrm{~min}$ and $30 \mathrm{sec}$, in order to remove the cumulus complex. The presumptive zygotes were washed three times with a pre-warmed tissue culture medium. Subsequently, presumptive zygote were transferred to a pre-warmed $50 \mu \mathrm{L}$ droplets of synthetic oviduct fluid medium in a petri dish which was covered with mineral oil and incubated for two days at $38.5^{\circ} \mathrm{C}$ in $5 \% \mathrm{CO}_{2}$ and $\mathrm{N}_{2}$. The cleavage rate was determined after $48 \mathrm{~h}$ of culture by recording the number of oocytes that developed into a two- and four-cell stage.

\section{Statistical Analysis}

The experiment was replicated five times for each treatment group. The results were expressed as mean values \pm standard error. The comparison of the percentage of motile sperm was performed by utilizing the t-test. The average values of the percentage of sperm with different solution in each experiment, the live and dead spermatozoa, plasma membrane integrity, acrosome integrity and DNA integrity were compared by using a Duncan's multiple range test by ANOVA procedure, once the F-value was significant $(P<0.05)$. All statistical evaluations were performed using Statistical Product and Services Solutions (SPSS 11.5 for Windows; SPSS, Chicago. IL, U.S.A).

\section{Results and Discussion}

The results of the effect of LDL on sperm motility parameters of fresh and frozen-thawed Nguni semen are presented in Table 1. For all the sperm motility parameters measured, both 10 and $12 \%$ LDL were worst substitutes for egg yolk. The highest sperm total motility was recorded with $8 \mathrm{LDL}(54.8 \pm 4.3)$ followed by the diluent containing $6 \%$ LDL $(41.5 \pm 5.2)$ while $20 \%$ egg yolk was $63.9 \pm 3.6$. For progressive motility and rapid motility, no significant differences were found between $6 \mathrm{LDL}, 8 \%$ LDL and $20 \%$ egg yolk.
The results of the effect of different concentration of LDL on live and dead sperm percentage (Means \pm SEM) of frozen thawed sperm are presented in Table 2. There was no statistical difference $(P>0.05)$ observed in the percentage of live sperm following freezing and thawing of Nguni bull semen diluted with $6 \%(64.9 \pm 2.4)$ LDL and $8 \%(65.5 \pm 21)$ LDL. The frozen-thawed semen sample diluted with $10 \%(40.2 \pm 5.3)$ LDL and $12 \%(27.0 \pm 5.5)$ LDL had the lowest percentage of live sperm, while the semen diluted with $20 \%(77.3 \pm 5.9)$ EY had a statistical $(P<0.05)$ higher percentage of live sperm compared to the semen diluted with $6 \%(64.9 \pm 2.4), 8 \%(65.5 \pm 2.1), 10 \%$ $(40.2 \pm 5.3)$, and $12 \%(27.0 \pm 5.5)$ LDL. Therefore, no statistical difference $(P>0.05)$ observed on the percentage of dead sperm diluted with $6 \%(34.5 \pm 2.1)$ and $8 \%(34.9 \pm 2.4)$ LDL following freezing and thawing. There was a significant difference $(P<0.05)$ observed in the frozen-thawed percentage of dead sperm diluted with $10 \%(59.9 \pm 5.5)$ and $12 \%(72.9 \pm 5.5)$ LDL. Semen diluted with $12 \%(72.9 \pm 5.5)$ LDL had a high percentage of dead sperm. The frozenthawed semen samples diluted with $20 \%(27.6 \pm 5.9)$ EY had the lower percentage of dead sperm compared to the frozen thawed semen diluted with $(6,8,10$ and $12 \%)$ LDL.

The results of the effect of different concentration on sperm plasma membrane integrity percentage (Means \pm SEM) of frozen-thawed Nguni bull semen are presented in Table 3. The highest percentage of sperm having an intact plasma membrane integrity was recorded in the semen diluted with $8 \%(66.0 \pm 2.8)$ LDL followed by the semen diluted with $6 \%(63.3 \pm 1.9)$ LDL, the semen diluted with $10 \%(38.8 \pm 3.9)$ and $12 \%(27.6 \pm 3.4)$ LDL had a lower percentage of intact plasm membrane integrity. The semen diluted with $20 \%(71.5 \pm 4.7)$ control had a significantly $(P<0.05)$ higher percentage of sperm having an intact plasma membrane compared to the semen diluted with $(6,8,10$ and $12 \%)$ LDL. However, $12 \%$ LDL had the highest percentage $(72.3 \pm 3.4)$ of damaged sperm plasma membrane integrity followed by the semen diluted with $10 \%(61.2 \pm 4.0)$ of LDL.

The results of the effect of different concentrations of LDL on the sperm acrosome integrity percentage (Means \pm SEM) of frozen-thawed Nguni bull semen are presented in Table 4. The analysis revealed that there was no significant difference in the acrosome integrity diluted with $6 \%$ $(64.0 \pm 2.0)$ and $8 \%(65.8 \pm 2.5)$ LDL $(P>0.05)$. The semen diluted with $10(38.9 \pm 3.9)$ and $12 \%(25.8 \pm 4.3)$ LDL had low percentage of intact acrosome integrity. Semen diluted with $20 \%(73.1 \pm 4.3)$ egg yolk had a significantly $(P<0.05)$ high percentage of sperm with an intact acrosome, while the semen diluted with $12 \%(74.5 \pm 4.1)$ had a high percentage of sperm with damaged acrosome integrity followed by the semen diluted with $10 \%(61.0 \pm 4.0)$ LDL. These suggest that semen diluted with LDL afford better protection to the sperm acrosome integrity compared to the semen diluted with (6, 10 and 12\%) LDL during the freeze-thawing process and that the most efficient concentration is $8 \%$ LDL. 
The results of the effect of different concentrations of LDL on the sperm acrosome integrity percentage (Means \pm SEM) of frozen-thawed Nguni bull semen are presented in Table 5. The results show no significant $(P>0.05)$ difference between the semen diluted with $6 \%(64.4 \pm 2.4)$ and $8 \%(66.2 \pm 2.4)$ LDL. There was a significant $(P<0.05)$ difference observed between semen diluted with $10 \%$ $(49.8 \pm 14.3)$ and $12 \%(27.8 \pm 2.9)$ with the semen diluted with $12 \%(27.8 \pm 2.9)$ LDL having a high percentage of sperm with an intact DNA integrity. Semen diluted with $20 \%$ egg yolk (control) had a significantly $(P<0.05)$ higher percentage of sperm with an intact DNA integrity compared to the semen diluted with $(6,8,10$ and $12 \%)$ LDL. The was no significant $(P>0.05)$ difference observed between the semen diluted with $6 \%(35.3 \pm 2.4)$ and $8 \%(33.7 \pm 2.4)$ LDL on the percentage of sperm with a damaged DNA integrity. There was a significant $(P<0.05)$ difference between the semen diluted with $10 \%(50.1 \pm 14.3)$ and $12 \%(72.1 \pm 2.9)$ LDL on the percentage of sperm with a damaged DNA integrity, although the semen diluted with $12 \%(72.1 \pm 2.9)$ LDL had a high percentage of sperm with a damaged DNA integrity. These results suggest that $8 \%$ LDL can offer better protection to the sperm DNA integrity during the freeze-thawing process.

The percentage of cleaved embryos was significantly different $(P<0.05)$ between the semen diluted with $8 \%$ LDL $(21.2 \pm 3.5)$ and $20 \% \mathrm{EY}$ $(25.8 \pm 2.4)$ (Table 6). There was a significant difference $(P<0.05)$ on the embryonic development rates from 2cell on the semen diluted with $8 \%$ LDL and $20 \% \mathrm{EY}$ $(12.8 \pm 1.9$ and $12.8 \pm 1.9$, respectively), with the semen diluted with $20 \% \mathrm{EY}$ having the highest percentage of embryos that develop into a 2-cell stage. At the 4-cell stage, there was also a significant difference $(P<0.05)$ observed between the semen diluted with $8 \%$ LDL and $20 \%$ EY (7.1 \pm 1.5 and $10.4 \pm 1.2$, respectively).

Table 1: The effect of different LDL concentrations on the sperm motility parameters of the frozen-thawed Nguni bull semen (Means \pm SEM)

\begin{tabular}{|c|c|c|c|c|c|c|c|}
\hline Treatments & Total motility (\%) & $\begin{array}{l}\text { Progressive } \\
\text { motility (\%) }\end{array}$ & $\begin{array}{l}\text { Non-progressive } \\
\text { motility }(\%)\end{array}$ & Rapid (\%) & Medium (\%) & Slow (\%) & Static (\%) \\
\hline Raw semen & $94.4 \pm 6^{\mathrm{a}}$ & $34.3 \pm 15^{\mathrm{a}}$ & $60.0 \pm 18.0^{\mathrm{a}}$ & $39.6 \pm 22.7^{\mathrm{a}}$ & $37.2 \pm 19.9^{\mathrm{a}}$ & $17.8 \pm 15.8^{\mathrm{c}}$ & $5.6 \pm 6.7^{\mathrm{d}}$ \\
\hline $6 \% \mathrm{LDL}$ & $41.2 \pm 5.2^{\mathrm{d}}$ & $9.0 \pm 5.3^{\mathrm{b}}$ & $32.1 \pm 5.2^{\mathrm{d}}$ & $2.1 \pm 2.6^{\mathrm{b}}$ & $12.0 \pm 7.2 \mathrm{~d}^{\mathrm{c}}$ & $26.1 \pm 8.3^{\mathrm{b}}$ & $59.5 \pm 13.3^{\mathrm{b}}$ \\
\hline $8 \% \mathrm{LDL}$ & $54.8 \pm 4.3^{\mathrm{c}}$ & $12.4 \pm 6.4^{\mathrm{b}}$ & $42.6 \pm 6.5^{\mathrm{c}}$ & $3.8 \pm 3.6^{\mathrm{b}}$ & $17.8 \pm 9.8^{\mathrm{bc}}$ & $41.5 \pm 17.6^{\mathrm{b}}$ & $6.6 \pm 22.0^{c}$ \\
\hline $10 \% \mathrm{LDL}$ & $28.0 \pm 6.5^{\mathrm{e}}$ & $4.5 \pm 2.7^{\mathrm{d}}$ & $23.4 \pm 5.6^{\mathrm{e}}$ & $3.0 \pm 3.6^{\mathrm{b}}$ & $6.8 \pm 3.1^{\mathrm{de}}$ & $18.2 \pm 6.5^{\mathrm{c}}$ & $1.8 \pm 6.5^{\mathrm{b}}$ \\
\hline $12 \% \mathrm{LDL}$ & $21.2 \pm 7.3^{\mathrm{f}}$ & $3.7 \pm 3.3^{\mathrm{d}}$ & $18.0 \pm 6.4^{\mathrm{f}}$ & $0.6 \pm 1.6^{\mathrm{c}}$ & $3.8 \pm 3.3^{\mathrm{d}}$ & ${ }^{\mathrm{e}} 20.4 \pm 151^{\mathrm{b}}$ & $7.4 \pm 9.9^{\mathrm{a}}$ \\
\hline
\end{tabular}

${ }^{\mathrm{a}-\mathrm{f}}$ values with different superscript within column differ significantly at $\mathrm{P}<0.05$

LDL = Low-density lipoprotein; EY= Egg yolk (control)

Table 2: The effect of different LDL concentrations on percentage of live and dead sperm of the frozen-thawed Nguni bull semen (Means \pm SEM)

\begin{tabular}{lll}
\hline Treatments & Live sperm $(\%)$ & Dead sperm $(\%)$ \\
\hline Raw semen & $91.4 \pm 3.1^{\mathrm{a}}$ & $8.5 \pm 3.1^{\mathrm{e}}$ \\
$6 \% \mathrm{LDL}$ & $64.9 \pm 2.4^{\mathrm{c}}$ & $34.5 \pm 2.1^{\mathrm{c}}$ \\
$8 \% \mathrm{LDL}$ & $65.5 \pm 2.1^{\mathrm{c}}$ & $34.9 \pm 2.4^{\mathrm{c}}$ \\
$10 \%$ LDL & $40.2 \pm 5.3^{\mathrm{d}}$ & $59.9 \pm 5.5^{\mathrm{b}}$ \\
$12 \%$ LDL & $27.0 \pm 5.5^{\mathrm{e}}$ & $72.9 \pm 5.5^{\mathrm{a}}$ \\
$20 \%$ EY & $77.3 \pm 5.9^{\mathrm{b}}$ & $27.6 \pm 5.9^{\mathrm{d}}$
\end{tabular}

$\overline{\mathrm{a}-\mathrm{e} \mathrm{e}}$ values with different superscripts within column differ significantly at $P<0.05$

LDL = Low-density lipoprotein; EY = Egg yolk (control)

Table 3: The effect of different LDL concentration on the sperm plasma membrane integrity of the frozen-thawed Nguni bull semen (Means \pm SEM)

\begin{tabular}{lll}
\hline Treatments & Intact plasma membrane integrity $(\%)$ & Damaged plasma membrane $(\%)$ \\
\hline Raw semen & $91.9 \pm 2.9^{\mathrm{a}}$ & $10.2 \pm 4.1^{\mathrm{f}}$ \\
$6 \% \mathrm{LDL}$ & $63.3 \pm 1.9^{\mathrm{d}}$ & $36.6 \pm 1.9^{\mathrm{c}}$ \\
$8 \% \mathrm{LDL}$ & $66.0 \pm 2.8^{\mathrm{c}}$ & $33.9 \pm 2.8^{\mathrm{d}}$ \\
$10 \% \mathrm{LDL}$ & $38.8 \pm 3.9^{\mathrm{e}}$ & $61.2 \pm 4.0^{\mathrm{b}}$ \\
$12 \% \mathrm{LDL}$ & $27.6 \pm 3.4^{\mathrm{f}}$ & $72.3 \pm 3.4^{\mathrm{a}}$ \\
$2 \% \mathrm{EY}$ & $71.5 \pm 4.7^{\mathrm{b}}$ & $28.4 \pm 4.7^{\mathrm{e}}$ \\
\hline
\end{tabular}

a-f values with different superscripts within column differ significantly at $P<0.05$

$\mathrm{LDL}=$ Low-density lipoprotein; EY = Egg yolk (control) 
Table 4: The effect of different concentrations of LDL on the sperm acrosome integrity percentage (Means \pm SEM) of frozen-thawed Nguni bull semen

\begin{tabular}{lll}
\hline Treatments & Intact acrosome $(\%)$ & Damaged acrosome $(\%)$ \\
\hline Raw semen & $88.0 \pm 3.3^{\mathrm{a}}$ & $11.9 \pm 3.4^{\mathrm{e}}$ \\
$6 \%$ LDL & $64.0 \pm 2.0^{\mathrm{c}}$ & $35.9 \pm 2.0^{\mathrm{c}}$ \\
8\% LDL & $65.8 \pm 2.5^{\mathrm{c}}$ & $34.1 \pm 2.5^{\mathrm{c}}$ \\
$10 \%$ LDL & $38.9 \pm 3.9^{\mathrm{d}}$ & $61.0 \pm 4.0^{\mathrm{b}}$ \\
$12 \%$ LDL & $25.8 \pm 4.3^{\mathrm{e}}$ & $74.5 \pm 4.1^{\mathrm{a}}$ \\
$20 \%$ EY & $73.1 \pm 4.3^{\mathrm{b}}$ & $27.2 \pm 4.1^{\mathrm{d}}$ \\
\hline
\end{tabular}

a-e values with different superscripts with column differ significantly at $P<0.05$

LDL= Low-density lipoprotein; EY = Egg yolk (control)

Table 5: The effect of different concentrations of LDL on the DNA sperm integrity of the frozen-thawed Nguni bull semen (Means \pm SEM)

\begin{tabular}{lll}
\hline Treatments & Intact DNA $(\%)$ & Damaged DNA $(\%)$ \\
\hline Raw semen & $89.0 \pm 4.6^{\mathrm{a}}$ & $11.9 \pm 3.4^{\mathrm{e}}$ \\
$6 \% \mathrm{LDL}$ & $64.4 \pm 2.4^{\mathrm{c}}$ & $35.9 \pm 2.0^{\mathrm{c}}$ \\
$8 \% \mathrm{LDL}$ & $66.2 \pm 2.4^{\mathrm{c}}$ & $33.7 \pm 2.4^{\mathrm{c}}$ \\
$10 \%$ LDL & $49.8 \pm 14.3^{\mathrm{d}}$ & $50.1 \pm 14.3^{\mathrm{b}}$ \\
$12 \%$ LDL & $27.8 \pm 2.9^{\mathrm{e}}$ & $72.1 \pm 2.9^{\mathrm{a}}$ \\
$20 \%$ EY & $76.0 \pm 7.1^{\mathrm{b}}$ & $23.9 \pm 7.1^{\mathrm{d}}$ \\
\hline
\end{tabular}

${ }^{\mathrm{a}-\mathrm{e}}$ values with different superscripts within column differ significantly at $P<0.05$

LDL = Low-density lipoprotein; EY = Egg yolk (control)

Table 6: Fertilization rate following using frozen-thawed Nguni bull semen diluted with 8 LDL and 20\% EYC

\begin{tabular}{lllll}
\hline Treatments & Maturation $(\% ; n)$ & Total cleavage $(\% ; n)$ & 2 -cell stage $(\% ; n)$ & 4 -cell stage $(\% ; n)$ \\
\hline $8 \%$ LDL & $32.1 \pm 7.1^{\mathrm{a}}(223)$ & $21.2 \pm 3.5^{\mathrm{b}}(149)$ & $12.8 \pm 1.9^{\mathrm{b}}(90)$ & $7.1 \pm 1.5^{\mathrm{b}}(50)$ \\
$20 \%$ EY & $34.4 \pm 4.9^{\mathrm{a}}(241)$ & $25.8 \pm 2.4^{\mathrm{a}}(170)$ & $17.0 \pm 2.3^{\mathrm{a}}(119)$ & $10.4 \pm 1.2^{\mathrm{a}}(73)$ \\
\hline
\end{tabular}

a,b values with different superscripts with column differ significantly at $P<0.05$

LDL = Low-density lipoprotein; EY = Egg yolk

This study was conducted to evaluate the effect of different concentrations of extracted LDL from chicken egg yolk on the cryopreservation of Nguni bull semen and fertilizing ability of semen cryopreserved with LDL. There was a statistical difference $(P<0.05)$ on the total sperm motility of the frozen-thawed Nguni bull semen diluted with $20 \%$ EY compared to the frozen-thawed semen diluted with $(6,8,10$ and 12\%) LDL. Semen diluted with $20 \% \mathrm{EY}$ resulted in higher sperm total motility (63.9) as compared to the semen diluted with different concentrations of LDL. According to Yunsheng et al. (2008), semen samples diluted with $9 \%$ gave better results when compared with $20 \% \mathrm{EY}$. This finding were in agreement with who reported that the ideal LDL concentration for freezing caprine semen was $8 \%$. This is also an ideal concentration for bull semen following freezing. The findings of our research were in agreement with Toniet et al. (2010) who stated that semen diluted with $8 \%$ LDL is able to offer more protection to ram sperm motility following freezing and Bencharif et al. (2008) witnessed that LDL offered better cryoprotectant action to boar semen as compared to egg yolk. These observations could be related to the granules as the increase of LDL concentration result in an aggregation of granules. Furthermore, an increase of LDL concentration could result to HDL aggregation. Semen diluted with $20 \%$
EY preserved the frozen-thawed semen better than the semen diluted with different LDL concentration and this may be due to the components that are found in the egg yolk, which may contribute to sperm post-thaw survival. For example, egg yolk is rich in various antioxidants such as vitamin $\mathrm{E}$ and $\mathrm{A}$ and lutein as well as several amino acids that play a major role in the preservation of sperm membrane. However, there was a statistical difference observed $(P<0.05)$ on the semen diluted with $20 \% \mathrm{EY}$ extender when compared to the semen diluted with different concentrations $(6,8,10$ and 12\%) of LDL. ElSharawy et al. (2012) reported a lower percentage of live sperm in a semen diluted with $20 \%$ of EY and other semen diluted with (4, 6 and 15\% LDL). Semen diluted with $20 \%$ EY resulted in a high percentage of live sperm compared to the semen diluted with different concentrations of LDL. Therefore, no statistical difference $(P>0.05)$ observed in the percentage of live sperm diluted with 6 (64.9\%) LDL and $8 \%(65.5 \%)$ LDL. The semen sample diluted with 10 (40.2 \pm 5.3$)$ LDL and $12 \%(27.0 \pm 5.5)$ LDL had the lowest percentage of live sperm compared to the semen diluted with 6 and $8 \%$ LDL. However, semen diluted with $12 \%$ LDL had the highest percentage of dead sperm. The semen diluted with $20 \%$ EY preserved the frozen-thawed Nguni bull semen better than the semen diluted with different LDL concentrations. Furthermore, 8 LDL had an 
intact plasma membrane integrity than 6,10 and $12 \%$ on thawed Nguni bull semen. Amirat et al. (2004) reported that LDL did not cause more injury to bull sperm following freezing and thawing as compared to EY. Bencharif et al. (2008) reported a better cryoprotectant action of plasma membrane integrity for dog sperm diluted with LDL compared to EY. This can be described by Bergeron et el. (2004) and Moustacas et al. (2011), who reported that LDL get attached to the plasma membrane, repairing the lost caused by natural outflow and thereby increasing the stability of the membrane, protecting the sperm from cold shock.

However, semen diluted with $20 \%$ EY resulted in a higher percentage of sperm with intact plasma membrane compared to semen diluted with LDL concentrations. According to Amirat et al. (2004), semen diluted with $20 \%$ EY gave a higher percentage of sperm with a damaged plasma membrane compared to the semen diluted with LDL. Semen diluted with $12 \%$ LDL had a higher percentage of sperm with a damaged plasma membrane. An increase in the LDL concentration above $8 \%$ resulted in a higher percentage of sperm with a damaged plasma membrane and this may be due to the aggregation of HDL and granules that have a negative effect on sperm viability (Hu et al., 2010). Moreover, there was a significant difference $(P<0.05)$ on the percentage of sperm with an intact acrosome integrity diluted with 20\% EY. Semen diluted with 20\% (73.1 \pm 4.3$)$ EY had a highest percentage of sperm with an intact acrosome compared to semen diluted with $(6,8,10$ and $12 \%)$ LDL. These results contradict with the results obtained by who find out that extenders containing LDL provided better protection to the acrosome than the extender containing 20\% EY $(P<0.05)$. Hu et al. (2010) also reported a higher percentage of sperm with an intact acrosome integrity following freezing and thawing of bull semen when the semen extender contained $8 \%$ LDL compared to the whole egg yolk $20 \%$. These results are in agreement with (Moreno et al., 2013) who reported that LDL provided better protection to the acrosome, possibly by a direct action through the exchange or repair of acrosome membrane phospholipids because the extender has lower progesterone content compared to egg yolk. There was no significant difference $(P<0.05)$ on percentage of sperm with an intact acrosome when semen was diluted with 6 LDL (64.0 \pm 2.0$)$ and 8\% LDL (65.8 \pm 2.5$)$. However, semen diluted with $12 \%$ LDL (74.5 \pm 4.1$)$ had the highest percentage of sperm with a damage acrosome. These results contradict with (Bencharif et al., 2008) who reported that the extender containing 12\% LDL provided better protection of the acrosome integrity and it was due to a direct action through the exchange or repair of acrosomal membrane phospholipids. Therefore, semen samples diluted with $20 \%$ LDL preserved the Nguni bull semen DNA integrity better than the semen diluted with different LDL concentrations. Frozen-thawed Nguni bull semen diluted with $20 \%$ EY (control) had a significantly $(P<0.05)$ high percentage of sperm with an intact DNA integrity compared to the semen diluted with $6,8,10$ and $12 \%$ LDL. These results contradict with $\mathrm{Hu}$ et al. (2010) who obtained better DNA integrity when the ovine semen was diluted with $8 \%$ LDL as opposed to the semen diluted with $20 \%$ EY. No significant difference $(P<0.05)$ was observed on the semen diluted with 6 and $8 \%$ LDL on the percentage of sperm with an intact DNA integrity. There was a significant difference $(P>0.05)$ observed between semen diluted with $10 \%(49.8 \pm 14.3)$ and $12 \%(27.8 \pm 2.9)$ LDL with the semen diluted with $12 \%(27.8 \pm 2.9)$ LDL having a high percentage of sperm with a damaged DNA integrity. Furthermore, there was a higher percentage of matured oocytes and cleavage rate on the semen diluted with $20 \%$ EY compared to the diluted with $8 \%$ LDL. However, these results contradict to the results obtained by Amirat et al. (2004) who obtained a higher cleavage rate with frozen-thawed semen diluted with $8 \%$ LDL than with $20 \%$ EY extender. These findings are in agreement with Marco-Jiménez et al. (2004) who showed that LDL extender was more effective in ovine sperm following freezing and resulted in higher fertilization rate as compared to egg yolk. In bulls, (Amirat et al., 2004) obtained higher cleavage rate when semen was diluted with LDL compared to semen diluted with EY extender but no differenced was witnessed on the blastocyst rate between semen diluted with LDL and EY extenders. Our results are not in agreement with the results obtained by Akhter et al. (2011), who obtained higher fertilization rates when buffalo semen was diluted with $1 \%$ LDL as compared with the control $20 \% \mathrm{EY}$.

\section{Conclusion}

Frozen-thawed Nguni bull semen diluted with 20\% EY resulted in a higher post-thawed semen motility, viability, sperm plasma membrane, acrosome, DNA integrity and fertilization rate compared to the frozen-thawed semen cryopreserved with $6,8,10$ and $12 \%$ LDL. However, better results were also obtained when semen was cryopreserved with $8 \%$ of LDL compared to other LDL concentrations. The inclusion of $8 \% \mathrm{LDL}$ in the semen diluent improved the frozen-thawed quality of the Nguni bull semen in terms of the post-thawed semen motility, viability, sperm plasma membrane, acrosome and DNA integrity. Semen cryopreserved with $8 \%$ of LDL can be used for in vitro fertilization compared to other semen diluted with 6,10 and 12\% LDL. However, semen cryopreserved with $20 \%$ EY extender resulted in a higher cryopreserved with $8 \%$ LDL can also be used as an alternative to $20 \% \mathrm{EY}$ extender in the cryopreservation and in vitro embryo production of cattle ovaries. 


\section{Acknowledgement}

The author would like to express his gratitude to the Agricultural Research Council (ARC) - Germplasm Conservation and Reproductive Biotechnologies (GCRB) staff for the assistance, ARC-Professional Development Program (PDP) scholarship (3014MA), Department of Agriculture Land Reform and Rural Development (DALRRD) and National Research Foundation (NRF) for the financial assistance.

\section{Funding Information}

I would like to acknowledge the Agricultural Research Council (ARC) scholarship (3014 MA), Department of Agriculture Land Reform and Rural development Forestry and Fisheries (DALRRD) and National Research Foundation (NRF) for the financial assistance.

\section{Authors Contributions}

Mduduzi Tshabalala, Masindi Lottus Mphaphathi, Khathutshelo Agree Nephawe, Cyril Pilane and Tshimangadzo: Lucky nedambale were in charge of the project design, data collection and writing of the manuscript.

\section{Conflict of Interest}

All authors have received and approved this final version of the manuscript. There is no conflict of interest in our submission.

\section{Ethics}

The experiment was evaluated and approved by the Agricultural Research Council Ethics Committee under the Cryo-gene bank program and by the Tshwane University of Technology Ethics Committee under the project number AREC2015/10/004.

\section{References}

Akhter, S., Ansari, M. S., Rakha, B. A. andrabi, S. M. H., Khalid, M., \& Ullah, N. (2011). Effect of low density lipoproteins in extender on freezability and fertility of buffalo (Bubalus bubalis) bull semen. Theriogenology, 76(4), 759-764. https://doi.org/10.1016/j.theriogenology.2011.04.009

Amirat, L., Tainturier, D., Jeanneau, L., Thorin, C., Gérard, O., Courtens, J. L., \& Anton, M. (2004). Bull semen in vitro fertility after cryopreservation using egg yolk LDL: a comparison with Optidyl®, a commercial egg yolk extender. Theriogenology, 61(5), 895-907. https://doi.org/10.1016/S0093-691X(03)00259-0
Bencharif, D., Amirat, L., Anton, M., Schmitt, E., Desherces, S., Delhomme, G., \& Tainturier, D. (2008). The advantages of LDL (low density lipoproteins) in the cryopreservation of canine semen. Theriogenology, 70(9), 1478-1488. https://doi.org/10.1016/j.theriogenology.2008.06.095

Bergeron, A., Crête, M. H., Brindle, Y., \& Manjunath, P. (2004). Low-density lipoprotein fraction from hen's egg yolk decreases the binding of the major proteins of bovine seminal plasma to sperm and prevents lipid efflux from the sperm membrane. Biology of Reproduction, 70(3), 708-717. https://doi.org/10.1095/biolreprod.103.022996

Bergeron, A., Villemure, M., Lazure, C., \& Manjunath, P. (2005). Isolation and characterization of the major proteins of ram seminal plasma. Molecular Reproduction and Development, 71(4), 461-470.ELSharawy, M. E. (2010). Use of low-density lipoproteins and glutamine to improve frozen buffalo bull semen. Doctor of Philosophy, Kafrelsheikh University. https://doi.org/10.1002/mrd.20310

El-Sharawy, M. E., El-Shamaa, I. S., Ibrahim, M. A. R., Abd El-Razek, I. M., \& El-Seify, E. M. (2012). Effect of low density lipoproteins in extender on freezability and fertility of Egyptian Buffalo bull semen. Anim. Sci. Series D, 55.

Hu, J. H., Li, Q. W., Zan, L. S., Jiang, Z. L., An, J. H., Wang, L. Q., \& Jia, Y. H. (2010). The cryoprotective effect of low-density lipoproteins in extenders on bull spermatozoa following freezing-thawing. Animal Reproduction Science, 117(1-2), 11-17. https://doi.org/10.1016/j.anireprosci.2009.04.001

Marco-Jiménez, F., Puchades, S., Mocé, E., Viudes-deCartro, M. P., Vicente, J. S., \& Rodriguez, M. (2004). Use of powdered egg yolk vs fresh egg yolk for the cryopreservation of ovine semen. Reproduction in Domestic Animals, 39(6), 438-441. https://onlinelibrary.wiley.com/doi/abs/10.1111/j.14 39-0531.2004.00537.x

Mazur, P. (1984). Freezing of living cells: mechanisms and implications. American Journal of PhysiologyCell Physiology, 247(3), C125-C142. doi.org/10.1152/ajpcell.1984.247.3.C125

Moreno, D., Bencharif, D., Amirat-Briand, L., Neira, A., Destrumelle, S., \& Tainturier, D. (2013). Preliminary results: the advantages of low-density lipoproteins for the cryopreservation of equine semen. Journal of Equine Veterinary Science, 33(12), 1068-1075. https://doi.org/10.1016/j.jevs.2013.04.004

Moustacas, V. S., Zaffalon, F. G., Lagares, M. A., LoaizaEccheverri, A. M., Varago, F. C., Neves, M. M., \& Henry, M. (2011). Natural, but not lyophilized, low density lypoproteins were an acceptable alternative to egg yolk for cryopreservation of ram semen. Theriogenology, 75(2),300307. https://doi.org/10.1016/j.theriogenology.2010.08.016 
Muchenje, V. (2007). Growth performance, carcass characteristics and meat quality of Nguni, Bonsmara and Angus steers raised on natural pasture (Doctoral dissertation, University of Fort Hare). https://core.ac.uk/download/pdf/145051664.pdf

Naing, S. W., Wahid, H., Azam, K. M., Rosnina, Y., Zuki, A. B., Kazhal, S., \& San, M. M. (2010). Effect of sugars on characteristics of Boer goat semen after cryopreservation. Animal reproduction science, 122(1-2), 23-28. https://doi.org/10.1016/j.anireprosci.2010.06.006

Ndlovu, T. (2007). Parasite prevalence, nutritionally-related blood metabolites and pre-slaughter stress response in Nguni, Bonsmara and Angus steers raised on veld (Doctoral dissertation, University of Fort Hare). http://libdspace.ufh.ac.za/handle/20.500.11837/650

Partyka, A., Niżański, W., \& Łukaszewicz, E. (2010). Evaluation of fresh and frozen-thawed fowl semen by flow cytometry. Theriogenology, 74(6), 1019-1027. https://doi.org/10.1016/j.theriogenology.2010.04.032

Prathalingam, N. S., Holt, W. V., Revell, S. G., Mirczuk, S., Fleck, R. A., \& Watson, P. F. (2006). Impact of antifreeze proteins and antifreeze glycoproteins on bovine sperm during freeze-thaw. Theriogenology, 66(8), 1894-1900. https://doi.org/10.1016/j.theriogenology.2006.04.041

Salamon, S., \& Maxwell, W. M. C. (1995). Frozen storage of ram semen I. Processing, freezing, thawing and fertility after cervical insemination. Animal Reproduction Science, 37(3-4), 185-249. https://doi.org/10.1016/0378-4320(94)01327-I

Seshoka, M. M., Mphaphathi, M. L., Ramukhithi, F. V., Netshirovha, T. R., Hlungwani, C., \& Nedambale, T. L. (2012). 76 the effect of glycerol concentrations in egg-yolk citrate extender on the quality of cryopreserved Nguni bull SemEN. Reproduction, Fertility and Development, 25(1), 185-185. https://www.publish.csiro.au/rd/RDv25n1Ab76
Spickett, A. M., De Klerk, D., Enslin, C. B., \& Scholtz, M. M. (1989). Resistance of Nguni, Bonsmara and Hereford cattle to ticks in a bushveld region of South Africa. https://repository.up.ac.za/handle/2263/42216

Tejada, R. I., Mitchell, J. C., Norman, A., Marik, J. J., \& Friedman, S. (1984). A test for the practical evaluation of male fertility by acridine orange (AO) fluorescence. Fertility and Sterility, 42(1), 87-91. https://doi.org/10.1016/S0015-0282(16)47963-X

Tekin, N. (2006). Effects of different taurine doses and freezing rate on freezing of row semen. Veterinary Journal of Ankara University (Turkey).

https://agris.fao.org/agrissearch/search.do?recordID=TR2007000035

Thun, R., Hurtado, M., \& Janett, F. (2002). Comparison of Biociphos-Plus ${ }^{\circledR}$ and TRIS-egg yolk extender for cryopreservation of bull semen. Theriogenology, 57(3), 1087-1094. https://doi.org/10.1016/S0093-691X(01)00704-X

Toniet, R. A., Karina, G., Gustavo, A. D. G., \& Schiavon, R. S. (2010). Small Ruminant Research. 93 (2), 206-209. https://doi.org/10.1016/j.smallrumres.2010.05.003

Watson, P. F. (1995). Recent developments and concepts in the cryopreservation of spermatozoa and the assessment of their post-thawing function. Reproduction, Fertility and Development, 7(4), 871-891. https://www.publish.csiro.au/rd/RD9950871

Yunsheng, Z., Wei, S., Sifeng, L., Chujie, J., \& Jianzhong, L. (2008). Preparation of C200 green reactive powder concrete and its static-dynamic behaviors. Cement and Concrete Composites, 30(9), 831-838. https://doi.org/10.1016/j.cemconcomp.2008.06.008 